\title{
Normovolemic modified ultrafiltration is associated with better preserved platelet function and less postoperative blood loss in patients undergoing complex cardiac surgery: A randomized and controlled study
}

\author{
Christian Friedrich Weber, MD, ${ }^{a}$ Csilla Jámbor, MD, ${ }^{\mathrm{b}}$ Christian Strasser, ${ }^{\mathrm{a}}$ Anton Moritz, MD, PhD, ${ }^{\mathrm{c}}$ \\ Nestoras Papadopoulos, MD, ${ }^{\mathrm{c}}$ Kai Zacharowski, MD, PhD, ${ }^{\mathrm{a}}$ and Dirk Meininger, MD, PhD ${ }^{\mathrm{a}}$
}

\begin{abstract}
Objective: The purpose of the investigation was to study the impact of normovolemic modified ultrafiltration (N-MUF) on hemostasis and perioperative blood loss.

Methods: Fifty patients scheduled for elective complex cardiac surgery were enrolled in this prospective, randomized, and controlled study. Patients were randomized into a control group $(n=25)$ or an N-MUF group $(\mathrm{n}=25)$. N-MUF was performed using a BC140plus Filter (Maquet Cardiopulmonary AG, Hirrlingen, Germany) in the N-MUF group. Blood samples were taken before (T1) and 30 minutes after (T2) N-MUF in the N-MUF group and at corresponding time points in the control group. Platelet function analyses (TRAPtest, ASPItest, ADPtest) using multiple electrode aggregometry (Multiplate, Dynabyte, Munich, Germany), thrombelastometry (ROTEM, Pentapharm GmbH, Munich, Germany), and conventional laboratory coagulation analyses were performed at each time point. Intraoperative and postoperative transfusion requirements, hemostatic therapy, and blood loss were recorded.
\end{abstract}

\begin{abstract}
Results: There were no significant group differences in demographic or surgical data. At T1, platelet aggregation revealed no significant group differences in the TRAPtest, ASPItest, or ADPtest. Platelet aggregation at T2 was significantly higher in the N-MUF group compared with the control group in the TRAPtest (65 [50/87] U vs 44 [28/51]; $P<.001$ ), the ASPItest (52 [36/69] U vs 22 [8/47] U; $P=.001$ ), or the ADPtest (39 [28/51] U vs 28 [19/39] U; $P=.009$ ). The postoperative chest tube blood loss was significantly lower in the N-MUF at 24 hours $(890$ [500/1100] $\mathrm{mL}$ vs 1075 [800/1413] $\mathrm{mL}$ in the N-MUF group vs the control group; $P=.039$ ) and 48 hours (900 [550/1350] mL vs 1400 [900/1750] mL; $P=.026)$ postoperatively. Conventional laboratory coagulation analyses and thrombelastometric parameters did not differ within the groups at T1 or T2.
\end{abstract}

Conclusions: N-MUF improved general platelet aggregation and reduced postoperative blood loss in a significant manner. However, performing N-MUF did not result in less postoperative transfusion requirements. (J Thorac Cardiovasc Surg 2011;141:1298-304)

Perioperative hemorrhage in patients undergoing cardiac surgery is related to a marked deterioration in prognosis because it is associated with a variety of negative outcomes,

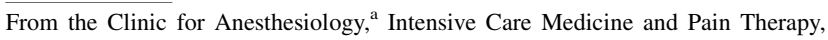
J.-W. Goethe University Hospital Frankfurt, Frankfurt am Main, Germany; Clinic for Anesthesiology, ${ }^{\mathrm{b}}$ University of Munich, Munich, Germany; and Department of Thoracic and Cardiovascular Surgery, ${ }^{\mathrm{c}} \mathrm{J}$.-W. Goethe University Hospital Frankfurt, Frankfurt am Main, Germany.

The work was performed at the Clinic for Anesthesiology, Intensive Care Medicine and Pain Therapy, J.-W. Goethe University Hospital Frankfurt, Frankfurt am Main, Germany.

Funding: The study was funded by the University of Frankfurt and performed without any industrial support.

Disclosures: C.F.W. and C.J. received speaking honoraria from Pentapharm and Dynabyte. C.J. received financial research support from Dynabyte.

Received for publication May 19, 2010; revisions received Aug 30, 2010; accepted for publication Sept 12, 2010; available ahead of print Dec 6, 2010.

Address for reprints: Christian Friedrich Weber, MD, Clinic for Anesthesiology, Intensive Care Medicine and Pain Therapy, J.-W. Goethe University Hospital Frankfurt, Theodor Stern Kai 760590 Frankfurt, Germany (E-mail: Christian.Weber@ kgu.de).

0022-5223/\$36.00

Copyright (C) 2011 by The American Association for Thoracic Surgery doi:10.1016/j.jtcvs.2010.09.057 such as renal failure, sepsis, atrial arrhythmias, prolonged requirement for mechanical ventilatory support, prolonged hospitalization, and increased mortality. ${ }^{1}$ In particular, patients undergoing complex cardiac surgery procedures with cardiopulmonary bypass $(\mathrm{CPB})$ are at increased risk for severe intraoperative and postoperative coagulopathy. In addition to dilution, consumption, and activation of coagulation factors, an imbalance between the coagulation and fibrinolytic system, especially a CPB-induced complex platelet dysfunction, has been shown to be the most important hemostatic abnormality in this setting. ${ }^{2}$

Since the 1970s, several blood filtration techniques have been proposed to prevent or attenuate the adverse effects of CPB on hemostasis. In particular, in pediatric patients undergoing cardiac surgery, the so-called modified ultrafiltration (MUF) method was adopted as standard practice in $75 \%$ of pediatric centers in North America to mitigate the distinctive hemodilution caused by $\mathrm{CPB} .{ }^{3}$ When performing hemoconcentration, this technique removes free water excess after terminating CPB. In this context, MUF 


\section{Abbreviations and Acronyms \\ aPTT = activated partial thromboplastin time \\ $\mathrm{CPB}=$ cardiopulmonary bypass \\ INR = international normalized ratio \\ MEA = multiple electrode aggregometry \\ $\mathrm{N}-\mathrm{MUF}=$ normovolemic ultrafiltration}

is known to be associated with clinical benefits, such as increased hematocrit and platelet count, ${ }^{4,5}$ improved pulmonary performance after reperfusion of the lungs, ${ }^{6}$ improved cardiovascular function, ${ }^{7}$ and reduced postoperative chest tube blood loss in pediatric patients. ${ }^{8}$

In contrast with pediatric patients, blood filtration during or after CPB is not a part of the standard procedure in adult patients. Its influence on the coagulation system, perioperative blood loss, and the clinical outcome in general remains controversial. $^{9-11}$ The aim of the present study was to determine the influence of normovolemic MUF (N-MUF) on perioperative hemostasis, with special regard on platelet function.

\section{MATERIALS AND METHODS}

This prospective, randomized, and controlled monocenter study complies with the Declaration of Helsinki and was approved by the local scientific and ethic review board. All patients gave written informed consent. Before collecting the data, the study was registered online at ClinicalTrials.gov (Identifier: NCT00998647).

\section{Study Design}

Patients were eligible for study inclusion if they underwent elective complex cardiac surgery. Complex cardiac surgery was defined as combined procedures, double-valve surgery, aortic surgery, and reoperations. Further inclusion criteria were defined as age more than 65 years, euroSCORE more than 5 , and expected duration of extracorporeal circulation more than 120 minutes. The exclusion criterion was patients' failure to obtain consent. A total of 50 consecutive patients at the Department of Thoracic and Cardiovascular Surgery of J.-W. Goethe University Hospital Frankfurt, Germany, were enrolled in this study between April 2009 and February 2010. Patients were preoperatively assigned to a control group $(\mathrm{n}=25)$ or an N-MUF group $(\mathrm{n}=25)$ by block-wise randomization.

Sociodemographic data, including preoperative antiplatelet therapy, were recorded. Surgical data, perioperative blood loss, and hemostatic therapy, including transfused blood products and coagulation factor concentrates up to 48 hours postoperatively, were assessed. Hematologic analyses were performed 30 minutes before and after N-MUF (or at corresponding time points in the control group) and included routine conventional laboratory, thrombelastometric, and platelet function analyses. No hemostatic therapy was performed during and up to 30 minutes after N-MUF (T2). The primary end point was the arachidonic acid induced ex vivo platelet aggregation in multiple electrode aggregometry (MEA, ASPItest). Secondary end points were the results of conventional laboratory, thrombelastometric, and remaining platelet function analyses and the perioperative blood loss.

\section{Anesthetic Management}

Anesthetic, operative, $\mathrm{CPB}$, and coagulation management were standardized. No changes in surgical, anesthetic, or perfusion techniques were made for the purpose of the study. On the day before the surgery, the patients were treated with $20 \mathrm{mg}$ dikaliumclorazepat (Tranxilium, Sanofi-Aventis $\mathrm{GmbH}$, Hoechst, Germany) for premedication. General anesthesia was induced with 0.3 to $1 \mu \mathrm{g} / \mathrm{kg}$ sufentanil (Sufenta, Janssen-Cilag $\mathrm{GmbH}$, Neuss, Germany), 1 to $2.5 \mathrm{mg} / \mathrm{kg}$ propofol (Disoprivan, AstraZeneca $\mathrm{GmbH}$, Wedel, Germany), and $0.6 \mathrm{mg} / \mathrm{kg}$ rocuronium (Esmeron, Essex GmbH, Munich, Germany). The maintenance of general anesthesia was achieved using 1 to $2 \mathrm{Vol} \%$ sevoflurane (Sevoran, Abbott, Wiesbaden, Germany) and intermittent boli of sufentanil until the transfer to an intensive care unit. All patients were orally intubated and mechanically ventilated using a LeonPlus anesthesia machine (Heinen \& Loewenstein, Bad Ems, Germany). Packed red blood cell concentrates were transfused to maintain a hematocrit greater than $18 \%$ during and $25 \%$ after CPB.

\section{Management of Extracorporeal Circulation and Normovolemic Modified Ultrafiltration}

The extracorporeal circuit included a membrane oxygenator (Quadrox oxygenator, Maquet Cardiopulmonary AG, Hirrlingen, Germany) and a roller pump system (HL20, Maquet Cardiopulmonary AG) equipped with a heat exchanger (Plegiox, Maquet Cardiopulmonary AG). The circuit was primed anterogradely with $500 \mathrm{~mL}$ crystalloid solution (Sterofundin, B.Braun Melsungen AG, Melsungen, Germany), $500 \mathrm{~mL}$ colloid solution (6\% HES 130/0.4, Voluven, Fresenius Medical Care AG, Bad Homburg,

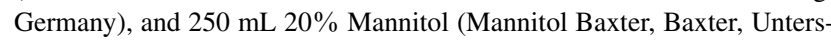
chleissheim, Germany) according to institutional standards. Heparin (Heparin-Natrium Braun, B.Braun Melsungen AG) was administered repetitively to maintain an activated clotting time of more than 400 seconds after an initial bolus of $400 \mathrm{IE} / \mathrm{kg}$. During CPB, a nonpulsatile flow was maintained at 2.6 to $3 \mathrm{~L} / \mathrm{min} / \mathrm{m}^{2}$, and the mean arterial blood pressure was targeted at 50 to $70 \mathrm{~mm} \mathrm{Hg}$ by the addition of norepinephrine (Arterenol, Sanofi-Aventis $\mathrm{GmbH}$ ), if needed. Myocardial protection was achieved with cold blood cardioplegia $\left(20^{\circ} \mathrm{C}\right)$. An antifibrinolytic therapy consisted of the application of $2 \mathrm{~g}$ tranexamic acid (Cyclocapron, MEDA Pharma GmbH \& Co KG, Bad Homburg, Germany) after induction of anesthesia, and another $2 \mathrm{~g}$ was added into the priming volume of the heartlung machine and during CPB, respectively. Extracorporeal circulation was performed in mild hypothermia. When surgery was completed, patients were rewarmed to $36^{\circ} \mathrm{C}$ and weaned from CPB. To reverse the anticoagulant effects of heparin, protamine sulfate (Protaminsulfat, Novo Nordisk Pharma GmbH, Vienna, Austria) was administered guided by activated clotting time.

N-MUF was started after the protamine infusion. A hemofilter (BC 140 plus; Maquet Cardiopulmonary AG) with a surface area of $1.35 \mathrm{~m}^{2}$, a priming volume of $98 \mathrm{~mL}$, a maximal transmembranous gradient of $600 \mathrm{~mm} \mathrm{Hg}$, a luminal diameter of $215 \mu \mathrm{m}$, and a membrane thickness of $50 \mu \mathrm{m}$ was used. The hemofilter was placed in the CPB circuit with blood coming in from the arterial site and returning to the venous site. Accelerated by the roller pump, the blood flow through the filter was $500 \mathrm{~mL} / \mathrm{min}$, and the ultrafiltration rate was $150 \mathrm{~mL} / \mathrm{min}$. To maintain normovolemia, a simultaneous infusion of $150 \mathrm{~mL} / \mathrm{min}$ crystalloid solution (Multibic Kaliumfrei, Fresenius Medical Care AG) was administered to the patient using a second roller pump. N-MUF was stopped after a filtration volume of $3000 \mathrm{~mL}$.

\section{Blood Sampling}

Blood samples were taken before (T1) and 30 minutes after (T2) N-MUF in the N-MUF group and at corresponding time points in the control group, respectively, from a preoperatively placed central venous line. The first $10 \mathrm{~mL}$ of blood was discarded. For conventional laboratory coagulation and ROTEM analyses, blood was collected into 3-mL tubes containing sodium citrate as anticoagulant (Sarstedt AG, Nürnbrecht, Germany) and a 4.7-mL EDTA tube (Sarstedt AG). For MEA (Multiplate) analyses, the blood was collected into 2-mL heparin-anticoagulated and calcium-balanced tubes (Bloodgas-Monovette, Sarstedt AG). 


\section{Hematologic Analyses \\ Conventional laboratory analyses. Platelet count, fibrinogen} concentration, international normalized ratio (INR), activated partial thromboplastin time (aPTT), and hematocrit were performed in the local central laboratory using the fully automated coagulation analyzer STA-R Evolution (Roche AG, Grenzach, Germany) and Sysmex XE 2001 (Sysmex $\mathrm{GmbH}$, Norderstedt, Germany).

Multiple electrode aggregometry. MEA was performed using the Multiplate analyzer, a whole blood impedance aggregometer (Dynabyte, Munich, Germany) based on impedance aggregometry described by Cardinal and Flower. ${ }^{12}$ The device has 5 test cells for parallel testing, and each test cell incorporates 2 independent sensor units. The analysis is based on the aggregation of the activated platelets onto metal sensor wires in the test cell, which increases the electrical impedance between the wires. For measurement, $300 \mu \mathrm{L}$ of preheated saline $\left(37^{\circ} \mathrm{C}\right)$ and $300 \mu \mathrm{L}$ of heparin-anticoagulated whole blood were placed into the test cell, and the sample was stirred using a Teflon-coated electromagnetic stirrer $(800 \mathrm{rpm})$ over a 3-minute incubation period. Platelet aggregation was initiated using $32 \mu \mathrm{mol} / \mathrm{L}$ thrombin receptor activating peptide (TRAP-6, TRAPtest), $0.5 \mathrm{mmol} / \mathrm{L}$ arachidonic acid (ASPItest), or $6.4 \mu \mathrm{mol} / \mathrm{L} \mathrm{ADP}$ (ADPtest) using commercially available reagents (Dynabyte). Increased impedance due to the attachment of platelets to the electrodes was continuously and separately measured by each sensor unit over 6 minutes. The data were transformed into arbitrary aggregation units (AU) and plotted as 2 separate aggregation curves against time. The aggregation measured by MEA was quantified as the area under the aggregation curve (U). The reference ranges for healthy subjects obtained from the manufacturer were 87 to $147 \mathrm{U}$ for the TRAPtest, 51 to $109 \mathrm{U}$ for the ASPItest, and 61 to $96 \mathrm{U}$ for the ADPtest.

Thrombelastometry. Thrombelastometry was performed by a 4-channel ROTEM device (Pentapharm GmbH, Munich, Germany) based on the classic thrombelastography described by Hartert. ${ }^{13}$ The technical and methodological details of ROTEM have been described. ${ }^{14,15}$ Four tests were performed according to the manufacturer's instructions: The EXTEM- and INTEM-test reflect the extrinsic and intrinsic initiation of coagulation, respectively, the FIBTEM-test (platelet-inhibited extrinsic activation) reflects plasmatic contributors to clot firmness, and the HEPTEM-test (heparinase-modified intrinsic activation) to identify heparin effects in comparison with the INTEM-test. Clotting time (seconds) in EXTEM, INTEM, and HEPTEM tests and the maximum clot firmness (millimeters) in each test were recorded.

\section{Postoperative Blood Loss}

The chest tube blood loss was assessed 6, 12, 24, and 48 hours postoperatively.

\section{Statistical Analyses}

The statistical analyses were performed using SigmaStat (Version 3.5, Systat Software GmbH, Erkrath, Germany) and SigmaPlot (Version 11, Systat Software GmbH) software. Sample size analysis was based on suggested changes in arachidonic acid induced ex vivo platelet aggregation with an expected difference of means for ASPItest of $15 \mathrm{U}$, an expected standard deviation of $25 \mathrm{U}$ (desired power $=0.8$, and $P<.05$ ), which was based on previous pilot investigation. The analysis revealed a required sample size of at least $\mathrm{n}=24$ in each group to detect statistically significant differences between the groups. Depending on the distribution of the data (Kolmogorov-Smirnov-Test), $t$ tests and paired $t$ tests or the Mann-Whitney rank-sum test and Wilcoxon signed-rank test were used to describe differences between the groups and the measuring points, respectively. Fisher's exact test was used to detect differences between the proportions of patients with respect to categoric data. The values are expressed as the mean \pm standard deviation or median $(25$ th $/ 75$ th percentiles).
TABLE 1. Demographic and surgical data and hemostatic therapy in the first 48 hours postoperatively

\begin{tabular}{|c|c|c|c|}
\hline & $\begin{array}{c}\text { Control group } \\
\mathbf{n}=\mathbf{2 5}\end{array}$ & $\begin{array}{c}\text { N-MUF group } \\
\quad \mathbf{n}=\mathbf{2 5}\end{array}$ & $\boldsymbol{P}$ \\
\hline Sex, male $(\%)$ & $16(64)$ & $13(52)$ & .673 \\
\hline Age, y & $75 \pm 5$ & $74 \pm 6$ & .434 \\
\hline BMI, $\mathrm{kg} / \mathrm{m}^{2}$ & $26 \pm 4$ & $26 \pm 4$ & .972 \\
\hline $\begin{array}{l}\text { Single antiplatelet therapy } \\
\text { until the day before surgery }\end{array}$ & $4(16)$ & $6(24)$ & .54 \\
\hline $\begin{array}{l}\text { Dual antiplatelet therapy until } \\
\text { the day before surgery }\end{array}$ & $3(12)$ & $3(12)$ & 1.0 \\
\hline euroSCORE & $7(6 / 9)$ & $7(6 / 8)$ & .425 \\
\hline $\mathrm{CPB}$ duration, min & $160 \pm 63$ & $146 \pm 50$ & .420 \\
\hline $\mathrm{CABG}$ and valve surgery $(\%)$ & $20(80)$ & $19(76)$ & .278 \\
\hline Double valve surgery (\%) & $4(16)$ & $4(16)$ & 1.0 \\
\hline Aortic surgery $(\%)$ & $1(4)$ & $2(8)$ & 1.0 \\
\hline Reoperations (\%) & $5(20)$ & $4(16)$ & .549 \\
\hline $\begin{array}{r}\mathrm{PRBC} \\
{[\mathrm{U}]}\end{array}$ & $\begin{array}{l}5(4 / 5) \\
(\mathrm{n}=25 / 25)\end{array}$ & $\begin{array}{l}4(4 / 5) \\
(\mathrm{n}=25 / 25)\end{array}$ & .513 \\
\hline $\begin{array}{l}\text { FFP } \\
{[\mathrm{U}]}\end{array}$ & $\begin{array}{l}3(3 / 4) \\
(\mathrm{n}=14 / 25)\end{array}$ & $\begin{array}{l}4(3 / 4) \\
(\mathrm{n}=12 / 25)\end{array}$ & .126 \\
\hline $\begin{array}{l}\mathrm{PC} \\
{[\mathrm{U}]}\end{array}$ & $\begin{array}{l}2(2 / 3) \\
(\mathrm{n}=10 / 25)\end{array}$ & $\begin{array}{l}2(2 / 2) \\
(\mathrm{n}=9 / 25)\end{array}$ & .801 \\
\hline $\begin{array}{l}\text { Fibrinogen } \\
\quad[\mathrm{g}]\end{array}$ & $\begin{array}{l}4(2 / 4) \\
(\mathrm{n}=15 / 25)\end{array}$ & $\begin{array}{l}4(3 / 4) \\
(\mathrm{n}=13 / 25)\end{array}$ & .341 \\
\hline $\begin{array}{l}\text { PCC } \\
{[\text { IE] }]}\end{array}$ & $\begin{array}{c}1200(1200 / 1800) \\
\quad(\mathrm{n}=11 / 25)\end{array}$ & $\begin{array}{c}1200(1200 / 1800) \\
(\mathrm{n}=8 / 25)\end{array}$ & .782 \\
\hline
\end{tabular}

$B M I$, Body mass index; $C P B$, cardiopulmonary bypass; $P R B C$, packed red blood cell; $F F P$, fresh-frozen plasma; $P C$, platelet concentrate; $P P C$, prothrombin complex concentrate. Values are presented as the median (25th/75th percentiles), mean \pm standard deviation, or number $(\%)$.

\section{RESULTS}

Demographic parameters, surgical data, transfusions, and hemostatic therapy are described in Table 1 . We detected no significant group differences of the prevalence of patients being treated with single antiplatelet $(100 \mathrm{mg} / \mathrm{d}$ aspirin) or dual antiplatelet $(100 \mathrm{mg} / \mathrm{d}$ aspirin and $75 \mathrm{mg} / \mathrm{d}$ clopidogrel $)$ therapy until the day before surgery (Table 1).

\section{Multiple Electrode Aggregometry Results}

The results of MEA analyses are shown in Figure 1. The baseline measurements at $\mathrm{T} 1$ revealed no significant group differences in the TRAPtest (48 [34/63] U vs 55 [33/91] U in the control group vs the N-MUF group, respectively; $P=.431)$, the ASPItest (26 [11/54] U vs $29[16 / 48] \mathrm{U}$ in; $P=.736$ ), or the ADPtest (30 [19/39] U vs 30 [16/46] U in; $P=.869$ ).

In contrast, platelet aggregation at $\mathrm{T} 2$ was significantly higher in the N-MUF group compared with the control group in the TRAPtest (44 [28/51] U vs 65 [50/87] U in the control group vs the N-MUF group, respectively; $P<.001)$, the ASPItest $(22[8 / 47] \mathrm{U}$ vs 52 [36/69] U in; $P=.001)$, or the ADPtest $(28[19 / 39] \mathrm{U}$ vs 39 [28/51] U in; $P=.009)$. 


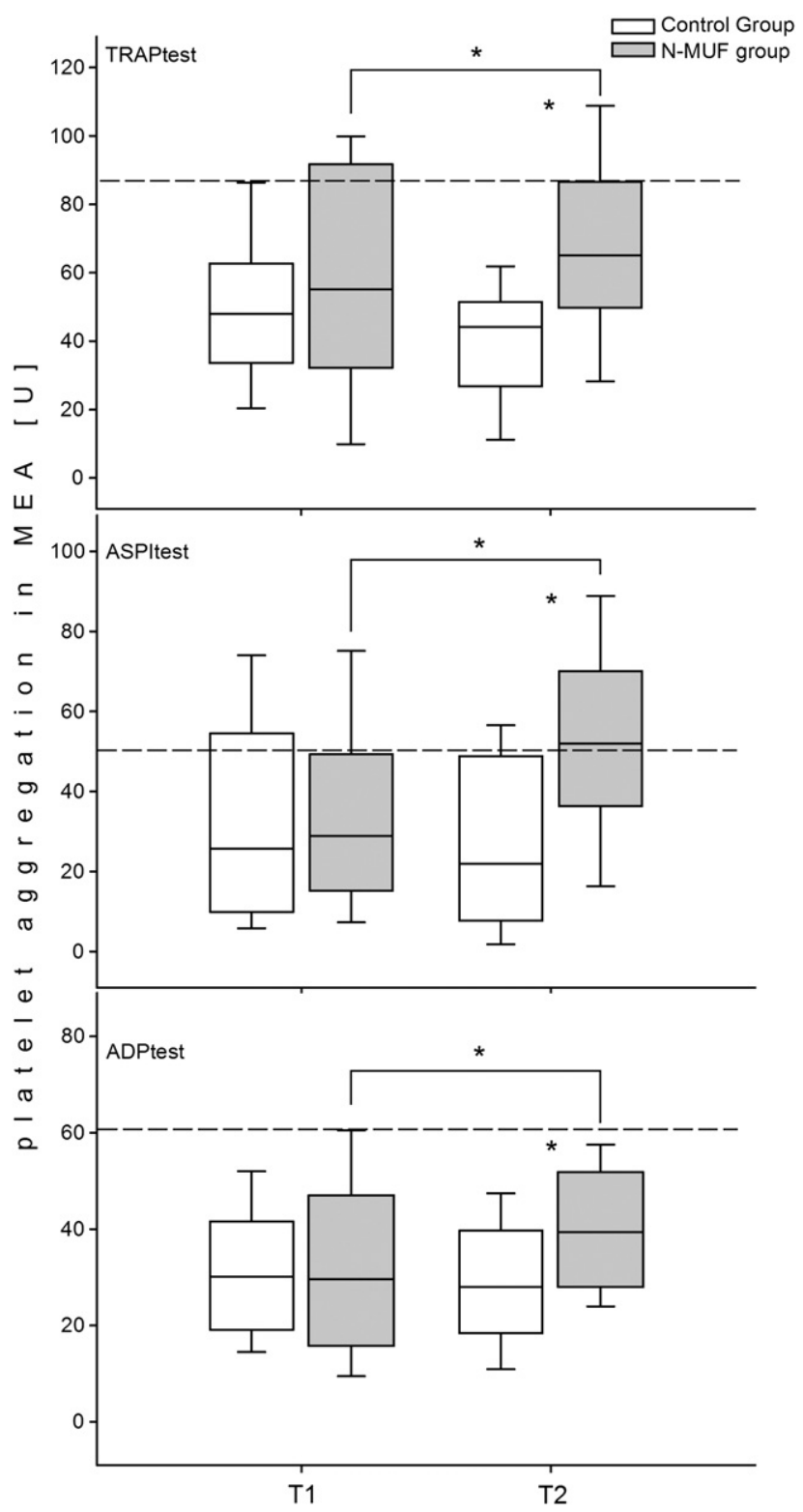

FIGURE 1. Ex vivo platelet aggregation in MEA at T1 and T2. Horizontal dashed lines indicate the lower limit of the reference range for normal platelet aggregation. $* P<.05 ; \mathrm{n}=50$.

Between $\mathrm{T} 1$ and $\mathrm{T} 2$, platelet aggregation significantly improved in the N-MUF group in each of the tests (55 [33/91] U vs 65 [50/87] U at T1 vs T2 for the TRAPtest; $P=.047,29[16 / 48]$ U vs 52 [36/69] U for the ASPItest; $P=.025$ and $30[16 / 46]$ U vs 39 [28/51] U for the ADPtest; $P=.016)$. In contrast, MEA remained unchanged in the control group between T1 and T2 (48 [34/63] U at T1 vs $44[28 / 51] \mathrm{U}$ at T2 for the TRAPtest; $P=.121,26$ [11/54] U vs 22 [8/47] $\mathrm{U}$ for the ASPItest; $P=.160$ and 30 [19/39] U vs 28 (19/39) U for the ADPtest; $P=.143)$.

\section{Conventional Laboratory Coagulation Analyses and Thrombelastometry}

$\mathrm{pH}$, calcium, temperature, hemoglobin, platelet count, fibrinogen INR, and aPTT did not differ at the corresponding time points between the groups. We did not detect any significant group differences in thrombelastometric parameters (Table 2).

\section{Postoperative Blood Loss, Blood Product Use, and Rate of Rethoracotomies}

We detected no significant group differences concerning the 6 hours $(450$ [263/725] $\mathrm{mL}$ vs 450 [275/688] $\mathrm{mL}$ in the control group vs the N-MUF group, respectively; $P=.883$ ) or 12 hours $(650$ [413/961] mL vs 600 [400/988] mL; $P=.863)$ postoperative blood loss. Blood loss was significantly lower 24 hours $(1075[800 / 1413] \mathrm{mL}$ vs 890 [500/ $1100] \mathrm{mL} ; P=.039)$ and 48 hours $(1400[900 / 1750] \mathrm{mL}$ vs $900[550 / 1350] \mathrm{mL} ; P=.026)$ postoperatively in the N-MUF group (Figure 2).

There were no group differences in the proportion of patients who underwent surgical reexploration for bleeding ( $\mathrm{n}=2$ in each group, $P=1.0$ ). Furthermore, we detected no significant group differences with respect to the perioperative transfusion rate of allogenic blood products, including packed red blood cell concentrates, fresh-frozen plasma, and platelet concentrates or coagulation factor concentrates (Table 1).

\section{DISCUSSION}

The main findings of the present study were that N-MUF after CPB was associated with i) a significant general improvement of platelet function as assessed by MEA and ii) a significant reduction in postoperative blood loss.

In view of normal reference ranges, MEA results showed a distinctively impaired platelet aggregation at $\mathrm{T} 1$ in both groups and thereby reflected the known effect of CPB on the induction of platelet dysfunctions. ${ }^{16,17}$ Our results showed a significant improvement of platelet aggregation in the N-MUF group at T2 in each of the performed tests, whereas platelet aggregation remained unchanged in the control group between $\mathrm{T} 1$ and $\mathrm{T} 2$. In the N-MUF group, platelet aggregation increased approximately $18 \%$ in the TRAPtest, $79 \%$ in the ASPItest, and 30\% in the ADPtest, whereas platelet aggregation in the control group did not alter. Notably, arachidonic acid-induced platelet aggregation in the N-MUF group even reached the reference range for normal platelet aggregation obtained by healthy volunteers (Figure 1). Analogue to our recent finding, ${ }^{16}$ the present data indicated that arachidonic acid-induced platelet aggregation might be the most sensitive test in MEA to reflect an improvement of CPB-induced platelet dysfunction.

Platelet aggregation at $\mathrm{T} 2$ was significantly higher in the N-MUF group compared with the control group (Figure 1). 
TABLE 2. Laboratory and thrombelastometric results at $\mathrm{T} 1$ and $\mathrm{T} 2$

\begin{tabular}{|c|c|c|c|c|c|c|}
\hline & \multicolumn{3}{|c|}{ T1 } & \multicolumn{3}{|c|}{$\mathbf{T 2}$} \\
\hline & Control group $n=25$ & N-MUF group $n=25$ & $\boldsymbol{P}$ & Control group $n=25$ & N-MUF group $n=25$ & $\boldsymbol{P}$ \\
\hline $\mathrm{pH}$ & $7.4(7.3 / 7.4)$ & $7.4(7.3 / 7.4)$ & .185 & $7.4(7.3 / 7.4)$ & $7.4(7.3 / 7.4)$ & .977 \\
\hline Calcium $[\mathrm{mmol} / \mathrm{L}]$ & $1.28(1.2 / 1.3)$ & $1.2(1.2 / 1.3)$ & .157 & $1.2(1.2 / 1.3)$ & $1.2(1.2 / 1.3)$ & .512 \\
\hline Temperature $\left[{ }^{\circ} \mathrm{C}\right]$ & $36.3(36 / 36.4)$ & $36.3(36 / 36.5)$ & .837 & $36.4(36.1 / 36.5)$ & $36.3(36.1 / 36.8)$ & .747 \\
\hline Hematocrit [\%] & $26.1(25.5 / 27.3)$ & $25.5(23.7 / 27.3)$ & .341 & $27(24.9 / 28.8)$ & $26.7(25.2 / 28.2)$ & .402 \\
\hline Platelet count $[/ \mathrm{nL}]$ & $118(90 / 146)$ & $123(95 / 143)$ & .614 & $105(70 / 141)$ & $113(91 / 132)$ & .186 \\
\hline Fibrinogen $[\mathrm{mg} / \mathrm{dL}]$ & $169(151 / 224)$ & $193(176 / 226)$ & .095 & $163(125 / 200)$ & $176(161 / 226)$ & .201 \\
\hline INR & $3.04(2.6 / 3.9)$ & $2.94(2.5 / 3.64)$ & .712 & $1.7(1.58 / 1.94)$ & $1.63(1.55 / 1.9)$ & .192 \\
\hline aPTT $[\mathrm{s}]$ & $>180$ & $>180$ & 1.0 & $50(44 / 69)$ & $59(48 / 78)$ & .261 \\
\hline $\mathrm{CT}_{\text {EXTEM }}[\mathrm{sec}]$ & $113(88 / 150)$ & $100(85 / 175)$ & .251 & $92(66 / 115)$ & $95(86 / 113)$ & .568 \\
\hline $\mathrm{MCF}_{\text {EXTEM }}[\mathrm{mm}]$ & $48(41 / 54)$ & $50(45 / 54)$ & .462 & $46(36 / 52)$ & $49(43 / 55)$ & .079 \\
\hline $\mathrm{CT}_{\text {INTEM }}[\mathrm{sec}]$ & - & - & - & $221(195 / 272)$ & $234(173 / 274)$ & .610 \\
\hline $\mathrm{MCF}_{\text {INTEM }}[\mathrm{mm}]$ & - & - & - & $44(41 / 48)$ & $46(42 / 52)$ & .176 \\
\hline $\mathrm{MCF}_{\text {FIBTEM }}[\mathrm{mm}]$ & $8(5.8 / 10)$ & $7(6 / 10)$ & .486 & $8(4.8 / 10)$ & $7(6 / 10)$ & .676 \\
\hline $\mathrm{CT}_{\text {HEPTEM }}[\mathrm{sec}]$ & $219(197 / 247)$ & $230(183 / 271)$ & .184 & $212(191 / 263)$ & $215(173 / 241)$ & .148 \\
\hline $\mathrm{MCF}_{\text {HEPTEM }}[\mathrm{mm}]$ & $46(39 / 54)$ & $51(48 / 55)$ & .527 & $42(35 / 47)$ & $46(40 / 52)$ & .095 \\
\hline
\end{tabular}

$I N R$, International normalized ratio; $a P T T$, activated partial thromboplastin time; $C T$, clotting time; $M C F$, maximal clot firmness. Values are presented as the median (25th/75th percentiles).

This effect could be attributed to N-MUF, because patients were randomized for this intervention and we detected no significant group differences in the proportion of patients preoperatively being treated with antiplatelet therapy, in the amount of perioperatively transfused allogenic blood products or coagulation factor concentrates (Table 1), or in conventional laboratory coagulation analyses or basic conditions for hemostasis (Table 2) at T1 and T2.

The beneficial effect of filtration on perioperative hemostasis, even considering different variations in the techniques used to perform filtration, has been shown in numerous prospective noncontrolled studies ${ }^{18,19}$ and a meta-analysis from 10 randomized trials, including 1004 patients undergoing cardiac surgery. ${ }^{20}$ Also, N-MUF was associated with a significant reduction in perioperative blood loss and transfusion requirements in both pediatric ${ }^{21}$ and adult patients undergoing cardiac surgery. ${ }^{18}$ Uncer-

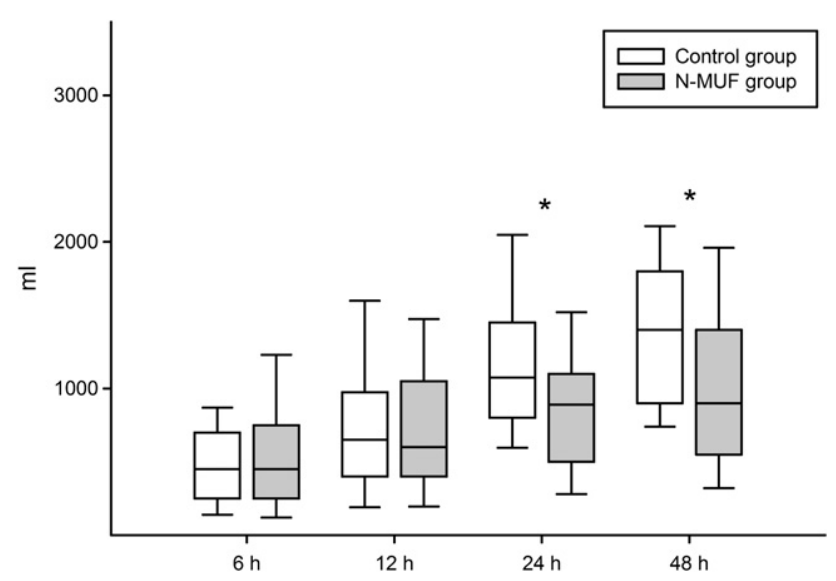

FIGURE 2. Postoperative blood loss. $* P<.05 ; \mathrm{n}=50$. tainty remains concerning the exact mechanism that forms the basis of the observed effects on perioperative hemostasis. Journois and colleagues ${ }^{8}$ suggested that the observed reduced postoperative blood loss after ultrafiltration may be related to the removal of mediators of the inflammatory response induced by CPB.

Secondary to mechanical fragmentation and destruction of platelet functional integrity, platelet dysfunction was attributed to the inflammatory response to CPB. In this context, complement activation plays an important role in CPBinduced platelet dysfunction. ${ }^{22}$ A correlation had been shown among the degree of complement activation, platelet dysfunction, and amount of postoperative blood loss. ${ }^{22,23}$ Remarkably, a reduction in complement activation was associated with a decrease in blood loss,${ }^{24}$ and the administration of monoclonal antibodies against complement factor C5a was even associated with a dose-dependent decrease in postoperative blood loss. ${ }^{25}$ Platelet dysfunctions based on CPB-induced generalized inflammation processes have been studied as acquired qualitative and quantitative deficiencies of adhesive platelet glycoprotein Ib and IIbIIIa receptors. $^{26}$ These platelet surface receptors are essential elements for platelet aggregation based on platelet-platelet interactions, which are reflected by aggregation in the MEA device. ${ }^{16}$ Filtration of the blood, independent of filter type, filtration time point, or aspired volume balance, had been shown to significantly reduce the inflammatory mediators, including cytokines such as interleukin-6, interleukin-8, and tumor necrosis factor- $\alpha$, and complement factors such as C3a and C5a. ${ }^{8,9,19,21}$ In view of these facts, the observed simultaneous increase in platelet aggregation in each of the 3 MEA tests after platelet stimulation with thrombin-receptor-activating peptide, arachidonic acid, or ADP led to the assumption that the filtration enhances 
glycoprotein Ib- or IIbIIIa-mediated platelet aggregation by a reduction of inflammatory mediators.

Our data showed that the cumulative blood loss at 24 and 48 hours postoperatively was significantly lower in the N-MUF group (Figure 2) compared with the control group. These results might reflect a beneficial effect of N-MUF on hemostasis but have to be interpreted with caution. The observed reduction in postoperative blood loss seemed not be of clinical relevance because the amount of transfused allogenic blood products or the proportion of patients who required transfusion did not differ between the groups.

Ultrafiltration was performed normovolemic and with no concentrating effect. Thus, it was unsurprising to observe that the performed conventional laboratory coagulation analyses and thrombelastometry (aPTT, INR, $\mathrm{CT}_{\text {HEPTEM, }}$ $\mathrm{CT}_{\text {INTEM}}$; Table 2) reflected the heparin effect at $\mathrm{T} 1$ and its reversal at $\mathrm{T} 2$ but did not show any significant influence of N-MUF on hemostasis.

\section{Study Limitations}

There were some limitations in our study. First, we did not perform any assays to study a potential change in the number and function of platelet surface glycoproteins or the concentration of inflammatory mediators. The results of such tests would have been helpful to corroborate our hypothesis that N-MUF improves ex vivo platelet aggregation by enhancing glycoprotein-mediated platelet-platelet interactions. However, it was the intention of our study to assess the influence of N-MUF on parameters of point of carebased and conventional coagulation analyses at the bedside. Second, the study population was small, and the sample size was based on the expected changes in platelet aggregation. In particular, the observed reduction in postoperative blood loss may be vulnerable to statistical errors. Third, ex vivo platelet aggregation in MEA was considered to be dependent of hematocrit. Transfusions of red blood cell concentrates were unavoidable within the study period in anemic patients because of ethical considerations. However, we detected no significant differences in the amount of perioperatively transfused packed red blood cells (Table 1) or in the hematocrit at $\mathrm{T} 1$ and $\mathrm{T} 2$ in each study group or between the groups (Table 2).

\section{CONCLUSIONS}

Despite these limitations, this study has important clinical implications. In patients undergoing complex cardiac surgery, N-MUF represents an approach to increase platelet function.

The authors thank Harald Keller, perfusionist at the Department of Thoracic and Cardiovascular Surgery, J.-W. Goethe University Hospital Frankfurt, for ambitious support during the study and critical review of the article.

\section{References}

1. Moulton MJ, Creswell LL, Mackey ME, Cox JL, Rosenbloom M. Reexploration for bleeding is a risk factor for adverse outcomes after cardiac operations. J Thorac Cardiovasc Surg. 1996;111:1037-46.

2. Holloway DS, Summaria L, Sandesara J, Vagher JP, Alexander JC, Caprini JA. Decreased platelet number and function and increased fibrinolysis contribute to postoperative bleeding in cardiopulmonary bypass patients. Thromb Haemost. 1988;59:62-7.

3. Naik SK, Knight A, Elliott MJ. A successful modification of ultrafiltration for cardiopulmonary bypass in children. Perfusion. 1991;6:41-50.

4. Kiziltepe U, Uysalel A, Corapcioglu T, Dalva K, Akan H, Akalin H. Effects of combined conventional and modified ultrafiltration in adult patients. Ann Thorac Surg. 2001;71:684-93.

5. Boodhwani M, Hamilton A, de Varennes B, Mesana T, Williams K, Wells GA, et al. A multicenter randomized controlled trial to assess the feasibility of testing modified ultrafiltration as a blood conservation technology in cardiac surgery. J Thorac Cardiovasc Surg. 2010;139:701-6.

6. Saitoh M, Tsuchida M, Koike T, Satoh K, Haga M, Aoki T, et al. Ultrafiltration attenuates cardiopulmonary bypass-induced acute lung injury in a canine mode of single-lung transplantation. J Thorac Cardiovasc Surg. 2006;132:1447-54.

7. Wang W, Zhu DM, Huang HM, Cai XM, Xu C, Jlang LM, et al. Effect of flow rate, negative pressure, and duration of modified ultrafiltration on hemodynamics and inflammatory mediators. Asaio J. 2007;53:41-5.

8. Journois D, Pouard P, Greeley WJ, Mauriat P, Vouhe P, Safran D. Hemofiltration during cardiopulmonary bypass in pediatric cardiac surgery. Effects on hemostasis, cytokines, and complement components. Anesthesiology. 1994;81:1181-9.

9. Grunenfelder J, Zund G, Schoeberlein A, Maly FE, Schurr U, Guntli S, et al. Modified ultrafiltration lowers adhesion molecule and cytokine levels after cardiopulmonary bypass without clinical relevance in adults. Eur J Cardiothorac Surg. 2000; 17:77-83.

10. Tassani P, Richter JA, Eising GP, Barankay A, Braun SL, Haehnel CH, et al. Influence of combined zero-balanced and modified ultrafiltration on the systemic inflammatory response during coronary artery bypass grafting. J Cardiothorac Vasc Anesth. 1999;13:285-91.

11. Leyh RG, Bartels C, Joubert-Hubner E, Bechtel JF, Sievers HH. Influence of modified ultrafiltration on coagulation, fibrinolysis and blood loss in adult cardiac surgery. Eur J Cardiothorac Surg. 2001;19:145-51.

12. Cardinal DC, Flower RJ. The electronic aggregometer: a novel device for assessing platelet behavior in blood. J Pharmacol Methods. 1980;3:135-58.

13. Hartert H. Thrombelastography, a method for physical analysis of blood coagulation. Z Gesamte Exp Med. 1951;117:189-203.

14. Rahe-Meyer N, Solomon C, Winterhalter M, Piepenbrock S, Tanaka K Haverich A, et al. Thromboelastometry-guided administration of fibrinogen concentrate for the treatment of excessive intraoperative bleeding in thoracoabdominal aortic aneurysm surgery. J Thorac Cardiovasc Surg. 2009;138:694-702.

15. Luddington RJ. Thrombelastography/thromboelastometry. Clin Lab Haematol. 2005;27:81-90.

16. Weber CF, Dietrich W, Spannagl M, Hofstetter C, Jambor C. A point-of-care assessment of the effects of desmopressin on impaired platelet function using multiple electrode whole-blood aggregometry in patients after cardiac surgery. Anesth Analg. 2010;110:702-7.

17. Maquelin KN, Berckmans RJ, Nieuwland R, Schaap MC, ten Have K, Eijsman L, et al. Disappearance of glycoprotein Ib from the platelet surface in pericardial blood during cardiopulmonary bypass. J Thorac Cardiovasc Surg. 1998;115:1160-5.

18. Tao Z, Gao CQ, Li JC, Wang JL, Li LB, Xiao CS. Effect of subzero-balanced ultrafiltration on postoperative outcome of patients after cardiopulmonary bypass. Perfusion. 2009;24:401-8.

19. Berdat PA, Eichenberger E, Ebell J, Pfammatter JP, Pavlovic M, Zobrist C, et al. Elimination of proinflammatory cytokines in pediatric cardiac surgery: analysis of ultrafiltration method and filter type. J Thorac Cardiovasc Surg. 2004;127: 1688-96.

20. Boodhwani M, Williams K, Babaev A, Gill G, Saleem N, Rubens FD. Ultrafiltration reduces blood transfusions following cardiac surgery: a meta-analysis. Eur J Cardiothorac Surg. 2006;30:892-7.

21. Journois D, Israel-Biet D, Pouard P, Rolland B, Silvester W, Vouhe P, et al. Highvolume, zero-balanced hemofiltration to reduce delayed inflammatory response to cardiopulmonary bypass in children. Anesthesiology. 1996;85:965-76.

22. Khuri SF, Wolfe JA, Josa M, Axford TC, Szymanski I, Assousa S, et al. Hematologic changes during and after cardiopulmonary bypass and their relationship to the bleeding time and nonsurgical blood loss. J Thorac Cardiovasc Surg. 1992;104:94-107. 
23. Warren OJ, Smith AJ, Alexiou C, Rogers PL, Jawad N, Vincent C, et al. The inflammatory response to cardiopulmonary bypass: part 1-mechanisms of pathogenesis. J Cardiothorac Vasc Anesth. 2009;23:223-31.

24. Videm V, Svennevig JL, Fosse E, Semb G, Osterud A, Mollnes TE. Reduced complement activation with heparin-coated oxygenator and tubings in coronary bypass operations. J Thorac Cardiovasc Surg. 1992;103: 806-13.
25. Fitch JC, Rollins S, Matis L, Alford B, Aranki S, Collard CD, et al. Pharmacology and biological efficacy of a recombinant, humanized, single-chain antibody C5 complement inhibitor in patients undergoing coronary artery bypass graft surgery with cardiopulmonary bypass. Circulation. 1999;100:2499-506.

26. Wenger RK, Lukasiewicz H, Mikuta BS, Niewiarowski S, Edmunds LH. Loss of platelet fibrinogen receptors during clinical cardiopulmonary bypass. J Thorac Cardiovasc Surg. 1989;97:235-9. 